\title{
VERIFICATION OF DESIGN LIFE EXPOSURE AND PERFORMANCE OF A BERM BREAKWATER
}

\author{
David Todd ${ }^{1}$, Amanda Blanksby ${ }^{2}$ and John Schepis ${ }^{2}$
}

\begin{abstract}
A mass armoured berm breakwater design was developed for a deepwater port project, under a build, own, operate and transfer project delivery model. The need to confirm short term (10 year) and long term (100 year) breakwater reshaping performance lead to a detailed assessment of design life exposure over these durations, combined with an extended physical scale model testing program. The aim of this testing program was to simulate, as far as practical, the design life performance of the breakwater with respect to berm reshaping and recession performance.
\end{abstract}

Keywords: design life storm exposure, mass armoured berm breakwater, physical model testing

\section{INTRODUCTION}

Breakwaters are commonly designed to withstand 50 or 100 year return period Metocean conditions without significant damage, while having design lives of similar durations. This results in a high probability of design event occurrence during the design life. More severe events with a lower probability of occurrence are called overload conditions, and the breakwater should be designed to survive these events without failure. However this still leaves a potential knowledge gap with respect to breakwater performance under more frequent lower return period conditions (ie. 10 and 50 year). This topic is not often dealt with in physical model testing.

For a proposed $2.5 \mathrm{~km}$ long breakwater (see Figure 1) in Western Australia, in up to $24 \mathrm{~m}$ water depths, a rigorous design life exposure assessment was undertaken to estimate the most likely combinations of return period events the breakwater was expected to encounter during its design life. These results were then used to develop a physical scale model testing program for the mass armoured berm breakwater design.

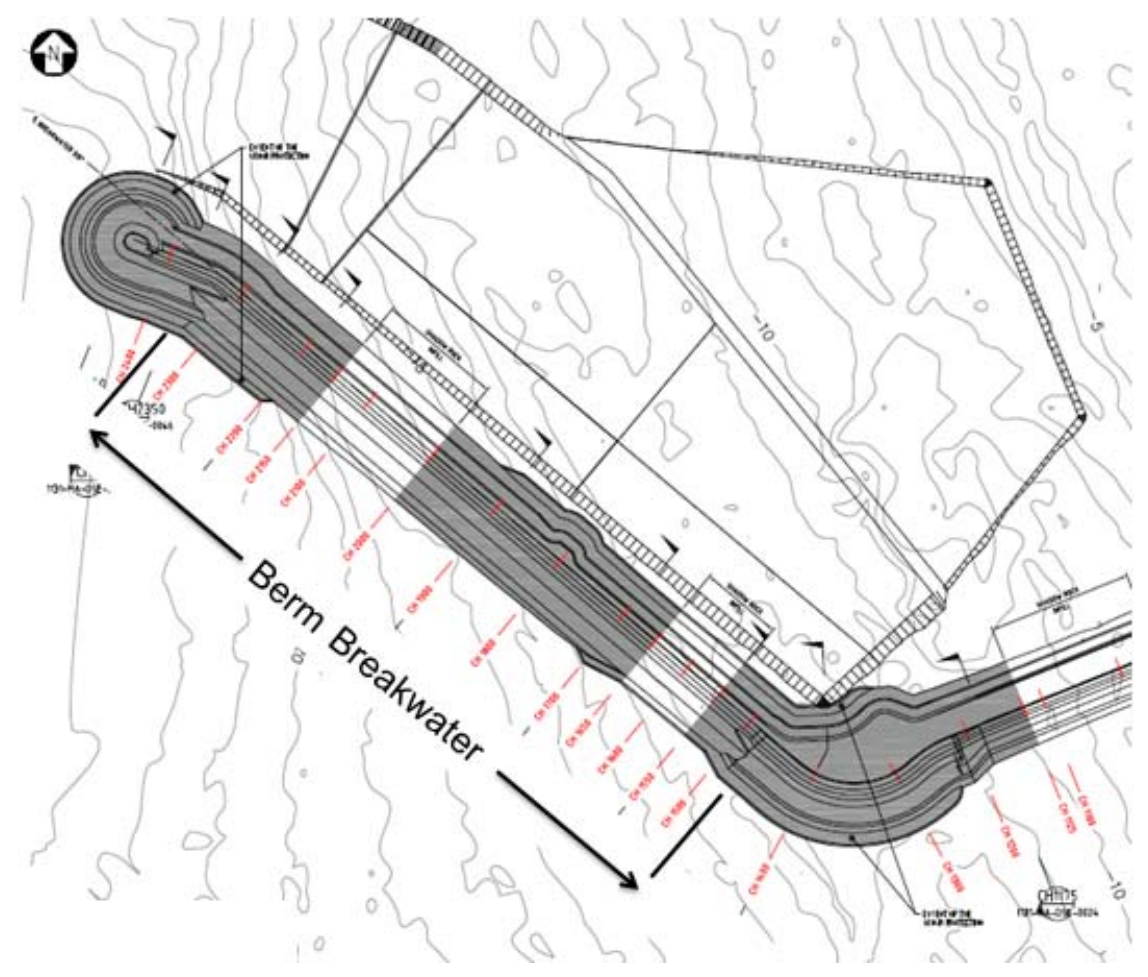

Figure 1. Berm Breakwater Layout.

\footnotetext{
${ }^{1}$ Consulting Engineer, PO Box 7120, Cloisters Square, WA 6850 Australia

${ }^{2}$ WorleyParsons, 250 St Georges Terrace, Perth, WA 6000 Australia
} 
The aim of the design life exposure assessment was to establish the most appropriate sequence of test cases with multiple 10 year and 50 year events, proceeding possible 100 year and 1000 year events for the 3D physical model test. The aim was to ensure that the test cases replicated, as far as reasonable, the likely storm events the breakwater may be subject to, during its 100 year design life. This is critical to the mass armoured berm design as it is known that these types of design can be subjected to progressive ongoing damage and reshaping during their design life, from events of return period less than the normal design return period for a statically stable breakwater design.

\section{SITE CONDITIONS}

The site is located on the mid-west coast, North of Geraldton. The seabed levels slope from the shoreline down to around $-24 \mathrm{mCD}$, where the breakwater head location is proposed. The outer portion of the breakwater, where the mass armoured berm design is proposed, is aligned approximately NorthWest, providing protection from dominant south westerly swells.

The site is located in a region of moderately high energy seas, especially within the context of other ports within Western Australia. The breakwater is exposed to distinct seasonal Metocean conditions, with summer cyclones from the Northwest and winter low pressure storm fronts from the West and Southwest. Previous project studies had defined the basic 100 year condition as Hs $5 \mathrm{~m}$ to $6 \mathrm{~m}$ and Tp 12 to 16 seconds, varying across the summer to winter storm conditions. There were also directional variations in wave heights.

\section{DESIGN LIFE EXPOSURE}

The concept of a re-shaping breakwater requires consideration of the extent of re-shaping which could occur over the design life or over acceptable maintenance intervals. This requires a different view on the selection of the design events for modelling and how they should be applied. For this to reflect reality, the expected number of events that have the potential to cause re-shaping need to be evaluated and applied to the structure. This provides advice on the final re-shaped profile and if the potential exists for recession to exceed accepted criteria.

The aim for consideration of the design life exposure was as follows:

- To ensure that the physical model test cases replicate reality, as far as reasonable, the different combinations (and sequencing) of possible ARI storm events the breakwater may be subject to, during its design life.

- $\quad$ Supports the selection of the model testing program runs to provide cumulative damage and berm recession results at specified intervals during the design life, (resulting from the variety and sequencing of possible storm event combinations, rather than just at the end of the 100 year design life).

- Provides support to the understanding of the maintenance and ultimate design requirements of the breakwater structure.

A number of ARI values (Annual Return Interval) were selected for test purposes, as follows; 1 year, 5 year, 10 year, 50 year, 100 year and 1000 year. The relationship between the ARI and probability is plotted in Figure 2 using $\mathrm{P}=1-(1 / \mathrm{ARI})$, and the range of ARI determined for the defined return period ranges. 


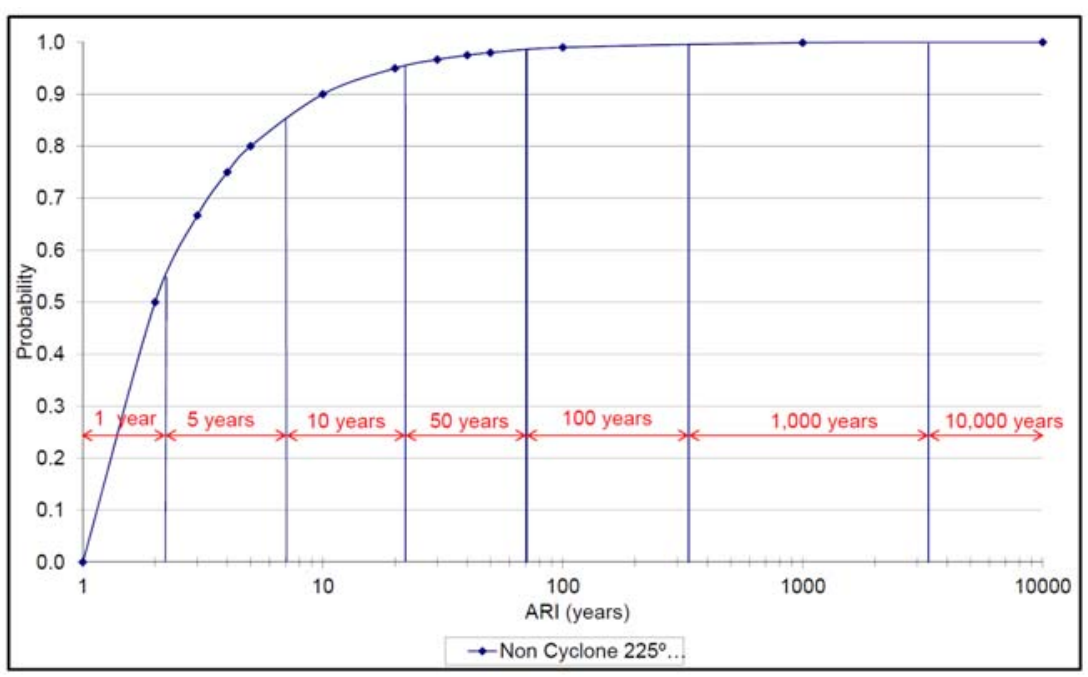

Figure 2. ARI - Probability banding for Non-Cyclonic Winter storm events.

A rational methodology to generate and categorise storm events into the ARI ranges as determined above was necessary to properly assess design life exposure. A logical methodology was developed by initially randomly generating a series of numbers between 0 and 1 , each representing the largest storm event to occur during one year. Overall 100 numbers were generated, representing the overall design life. Each worse case yearly storm event was allocated into a return period range, according to its probability value.

The random number generator was run for 20 times the design life of 100 years, producing a total population of 2000 storm events. It was found that statistical trends smoothed out after 20 design life simulations. A sample of the non-cyclonic winter storm occurrence statistics is shown in Table 1 below.

\begin{tabular}{|c|c|c|c|}
\hline \multicolumn{4}{|c|}{ Table 1. No. of Occurrences over Design life } \\
\hline ARI (Years) & $\begin{array}{l}\text { Range - } \\
\text { Min }\end{array}$ & $\begin{array}{l}\text { Average } \\
\text { No. }\end{array}$ & $\begin{array}{l}\text { Range } \\
\text { Max }\end{array}$ \\
\hline 1 & 41 & 52 & 65 \\
\hline 5 & 22 & 33 & 46 \\
\hline 10 & 4 & 10 & 18 \\
\hline 50 & 0 & 4 & 9 \\
\hline 100 & 0 & 1 & 4 \\
\hline 1000 & 0 & 0 & 1 \\
\hline 10000 & 0 & 0 & 0 \\
\hline
\end{tabular}

A similar approach was followed for the summer cyclonic storm occurrences, with a modified ARI - Probability relationship to account for the less frequent cyclonic events. The simulation approach provided the ability to see the randomness of the outcome of each independent storm event. While the most likely average number of events was adopted, the variation across multiple design lives is notable as should be remembered in any forensic examination of prototype breakwater performance. For example in Table 1 it can be seen that some design life simulations experienced as many as four 100 year ARI events, while the average was one 100 year ARI event. The results of this analysis led to specific increases in the testing program with multiple events for 10 year, 50 year and 100 year return conditions.

\section{BERM BREAKWATER}

Physical 2D flume and 3D basin modelling had been completed on a statically stable berm breakwater design of the Icelandic type. Consideration was given to the use of both rock and concrete armour units in that design, with both tested. The design utilised large armour stone of various gradings to provide overall hydraulic stability and minimal damage performance. 
Subsequently, a value engineering exercise was undertaken on the project, to examine options for the breakwater. One option developed was to consider an alternative mass armoured breakwater design. This alternative offered construction benefits as a result of the lower placement requirements for the primary armour, the reduced risk on quarry yield of larger stone and reduced handling complexity due to smaller primary armour size (when compared with the statically stable berm breakwater). A typical section of the mass armoured design is shown in Figure 3.

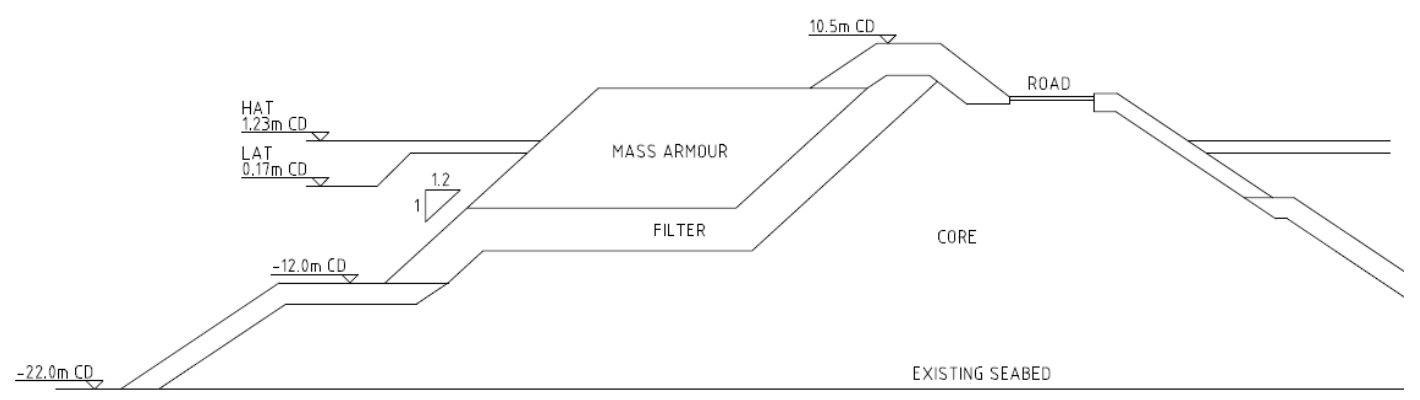

Figure 3. Mass Armoured Berm Breakwater Typical Section.

The armour grading selected had a stability number of 1.7 to 2.0 for 10 year conditions, increasing to 2.1 to 2.3 for 100 year and 2.6 to 3.6 for 1000 year conditions. The section has a steep front face slope to reduce equipment reach requirements during construction. The lower berm at $-12 \mathrm{mCD}$ forms a critical part of the structure, capturing reshaped armour stone and accelerating the formation of a sprofile.

\section{TEST SEQUENCE AND PROGRAM}

The approach to the testing sequence was to expose the berm breakwater to a series of noncyclonic winter and cyclonic summer storms which reflected a scenario that was supported by the results of the design life exposure analysis. The storm sequence was applied in an order that initially gradually increased the storm severity to 50 year ARI and then varied it in an oscillating fashion across return periods from 10 to 100 year ARI. The testing sequence was also structured so as to rationalise the number of wave generation paddle moves within the basin between wave directions (and thus the type of storm event, cyclone / non-cyclonic), but without compromising the integrity of the overall testing objective.

The general approach to the testing sequence was as follows:

- $\quad$ Stage 1 and 2 - consideration to both the $225^{\circ}$ and $277.5^{\circ}$ directions (representing non-cyclonic and cyclone); with the number of storms for the 1, 10, 50 and 100 return periods being as per the output from the design life exposure assessment. At the end of Stage 2 the breakwater was exposed to the storms likely to occur within its first 10 (to 20) years of design life.

- $\quad$ Stage 3 and 4 - further storms were applied from both $225^{\circ}$ and $277.5^{\circ}$ directions. Where the design life assessment had indicated for example 1.5 events, this was rounded up to 2 events for conservatism. At the end of Stage 4 the breakwater was considered to have been exposed to its full 100 years of design life exposure.

- Stage 5 was a single test from $290^{\circ}$ direction specifically to test the head and lee side of the breakwater.

- $\quad$ Stage 6 and 7 covered the overload conditions. Firstly a sea level rise case for the 100 year return period was tested and then the 1 in 1000 year return period for both $225^{\circ}$ and $277.5^{\circ}$ direction. The design life exposure assessment highlighted that the average storm occurrence is one 1000 year event for the cyclonic case but two were considered to account for the two different directions. A the end of Stage 7 the breakwater was considered to be exposed to its overload conditions, with exposure to two 1000 year representative storms.

The oscillating test sequence adopted is represented in the flowchart shown in Figure 4. 


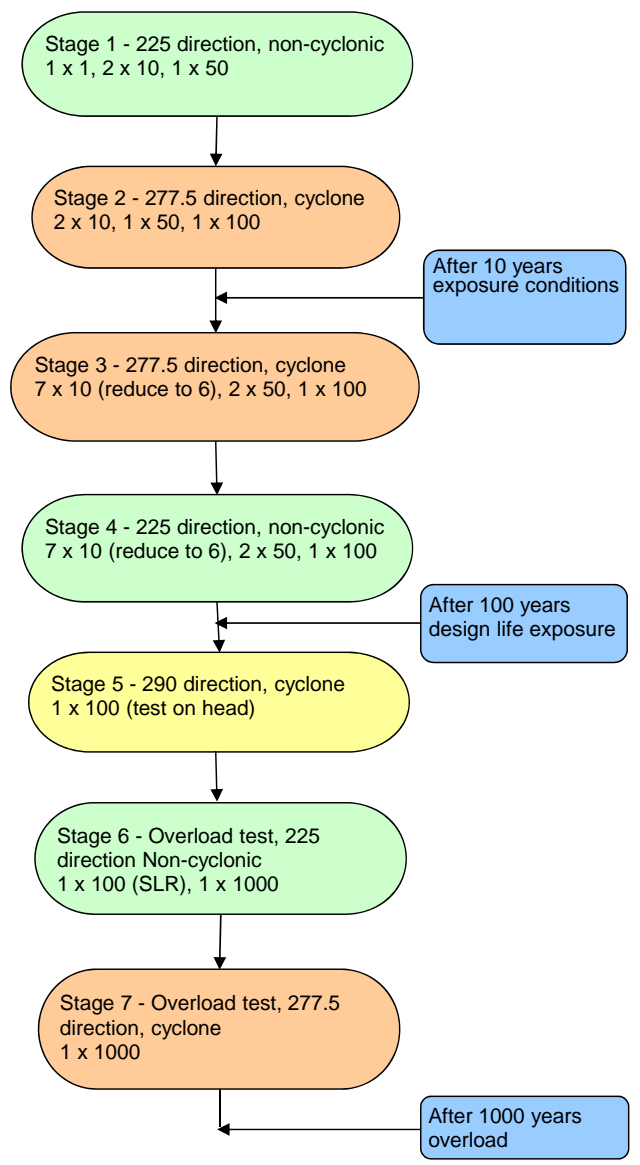

Figure 4. Oscillating Test Sequence.

The resultant 3D testing program consisted of 30 specific storm test conditions, of varying return period, water level and wave direction. This is shown in Table 2 . The physical model was conducted at HR Wallingford in the United Kingdom, in a 30 x 50m wave basin. The testing was completed over a five week period, excluding model construction.

\begin{tabular}{|c|c|c|c|c|c|c|}
\hline \multicolumn{6}{|l|}{ Table 2. 3D Testing Program } \\
$\begin{array}{c}\text { Test } \\
\text { No }\end{array}$ & Sea state & $\begin{array}{c}\text { Direction } \\
\text { (degrees) }\end{array}$ & Type & Spectrum & $\begin{array}{c}\text { ARI } \\
\text { (years) }\end{array}$ & Comment \\
\hline 1 & 201 & 225 & Non-cyclonic & Jonswap & 1 & \\
\hline 2 & 202 & 225 & Non-cyclonic & Jonswap & 10 & MSL \\
\hline 3 & 202 & 225 & Non-cyclonic & Jonswap & 10 & SSWL \\
\hline 4 & $202 \mathrm{~b}$ & 225 & Non-cyclonic & PM & 50 & MSL \\
\hline 5 & 306 & 277.5 & Cyclone & Jonswap & 10 & MSL \\
\hline 6 & 302 & 277.5 & Cyclone & Jonswap & 10 & SSWL \\
\hline 7 & 307 & 277.5 & Cyclone & Jonswap & 50 & MSL \\
\hline 8 & 304 & 277.5 & Cyclone & Jonswap & 100 & SSWL \\
\hline 9 & 306 & 277.5 & Cyclone & Jonswap & 10 & MSL \\
\hline 10 & 302 & 277.5 & Cyclone & Jonswap & 10 & SSWL \\
\hline 11 & 306 & 277.5 & Cyclone & Jonswap & 10 & MSL \\
\hline 12 & 302 & 277.5 & Cyclone & Jonswap & 10 & SSWL \\
\hline
\end{tabular}




\begin{tabular}{|c|c|c|c|c|c|c|}
\hline 13 & 306 & 277.5 & Cyclone & Jonswap & 10 & MSL \\
\hline 14 & 302 & 277.5 & Cyclone & Jonswap & 10 & SSWL \\
\hline 15 & 307 & 277.5 & Cyclone & Jonswap & 50 & MSL \\
\hline 16 & 303 & 277.5 & Cyclone & Jonswap & 50 & SSWL \\
\hline 17 & 308 & 277.5 & Cyclone & Jonswap & 100 & MSL \\
\hline 18 & $202 \mathrm{LWL}$ & 225 & Non-cyclonic & Jonswap & 10 & $\mathrm{LWL}$ \\
\hline 19 & 202 & 225 & Non-cyclonic & Jonswap & 10 & $\mathrm{MSL}$ \\
\hline 20 & 202 & 225 & Non-cyclonic & Jonswap & 10 & SSWL \\
\hline 21 & $202 \mathrm{SLR}$ & 225 & Non-cyclonic & Jonswap & 10 & SLR \\
\hline 22 & 202 & 225 & Non-cyclonic & Jonswap & 10 & $\mathrm{MSL}$ \\
\hline 23 & 202 & 225 & Non-cyclonic & Jonswap & 10 & $\mathrm{SSWL}$ \\
\hline 24 & $202 \mathrm{~b}$ & 225 & Non-cyclonic & PM & 50 & $\mathrm{MSL}$ \\
\hline 25 & $202 \mathrm{~b}$ & 225 & Non-cyclonic & PM & 50 & $\mathrm{SSWL}$ \\
\hline 26 & $204 \mathrm{~b}$ & 225 & Non-cyclonic & PM & 100 & $\mathrm{SSWL}$ \\
\hline 27 & 301 & 290 & Cyclone & Jonswap & 100 & $\mathrm{SSWL}$ \\
\hline 28 & $204 \mathrm{bSLR}$ & 225 & Non-cyclonic & PM & 100 & $\mathrm{SLR}$ \\
\hline 29 & 210 & 225 & Non-cyclonic & Jonswap & 1000 & $\mathrm{SSWL}$ \\
\hline 30 & 305 & 277.5 & Cyclone & Jonswap & 1000 & $\mathrm{SSWL}$ \\
\hline
\end{tabular}

\section{TEST RESULTS}

Damage during testing was recorded by laser profiling, surface mapping and generation of sets of cross sections set within test panels, along the length of the berm breakwater. Each set of ten crosssections was averaged, and the average Area of Erosion, $\mathrm{Ae}\left(\mathrm{m}^{2}\right)$ were thus determined across each of six test panels.

\section{Area of Erosion Results}

The Area of Erosion, Ae, test results are best seen in Figure 5, with the test program overlaid on the cumulative number of waves horizontal axis.

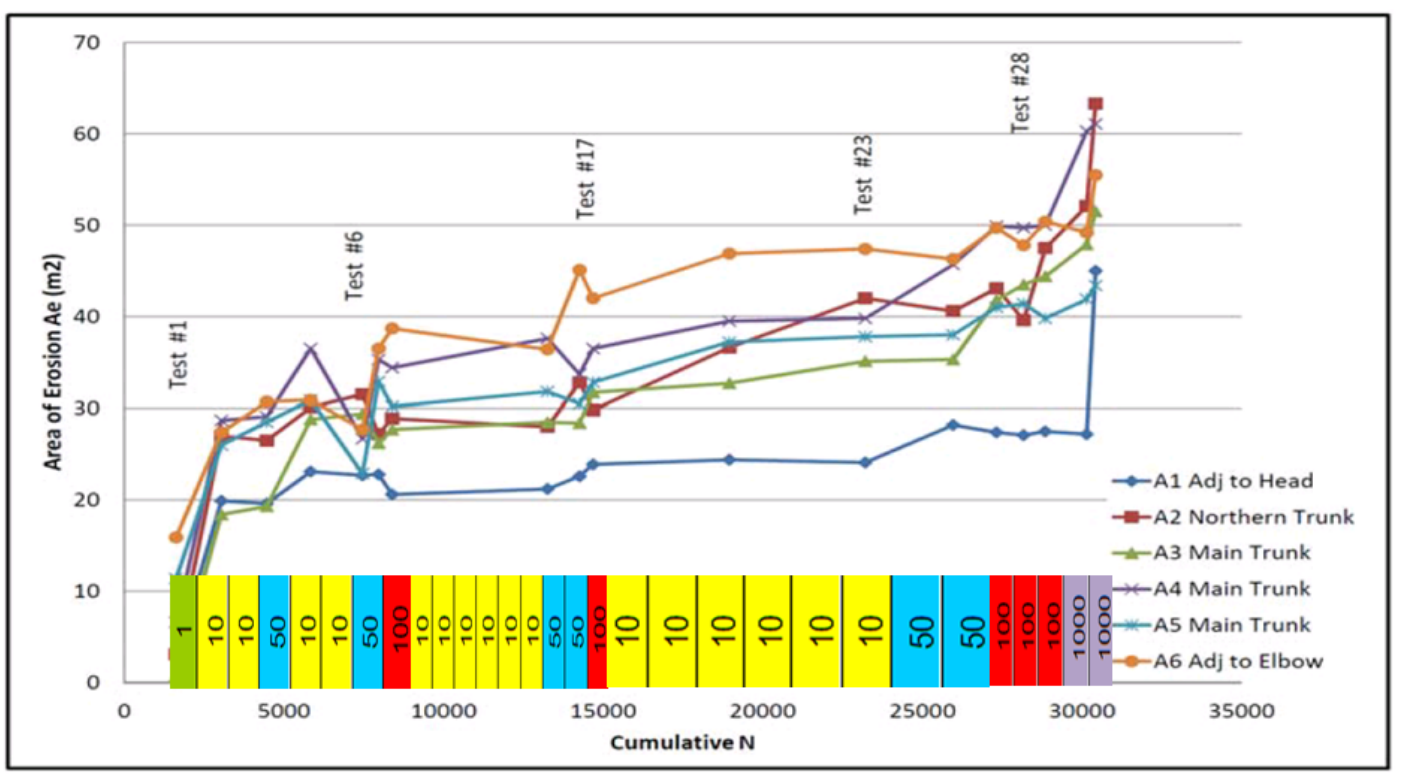

Figure 5. Test Results, Area of Erosion.

The analysis shows several key results and observations which confirm the drivers for this design life exposure assessment and extended testing program: 
- The sharp increase in Ae following 50 and 100 year ARI events (Tests \#4, 7, 8, 15-17), gradually decreasing throughout the testing program (and thus breakwater design life).

- The reduction in Ae during milder storm events (10 year ARI in Tests \#5 \& 6) after the early 50 and 100 year ARI events, indicating profile restoration.

- The variable increase in Ae during the latter 10 year ARI events (Tests \#18-23) even after the breakwater has been exposed to four 50 year and two 100 year ARI events. This showed the importance of the extended test program with oscillating test conditions.

- The overload tests produced additional notable damage, although this reshaping was still accommodated within the mass armoured berm design profile.

\section{Profile Development Results}

The profile development performance of the mass armoured berm breakwater can be seen in Figure 5, for a typical test panel. The initial reshaping of the 1:1.2 constructed front face can be clearly seen. Also on note is the performance of the lower berm at $-12 \mathrm{mCD}$ (see Figure 3) in forming an extended platform to capturing dislodged berm armour stone and aiding in the formation of a s-profile berm shape.

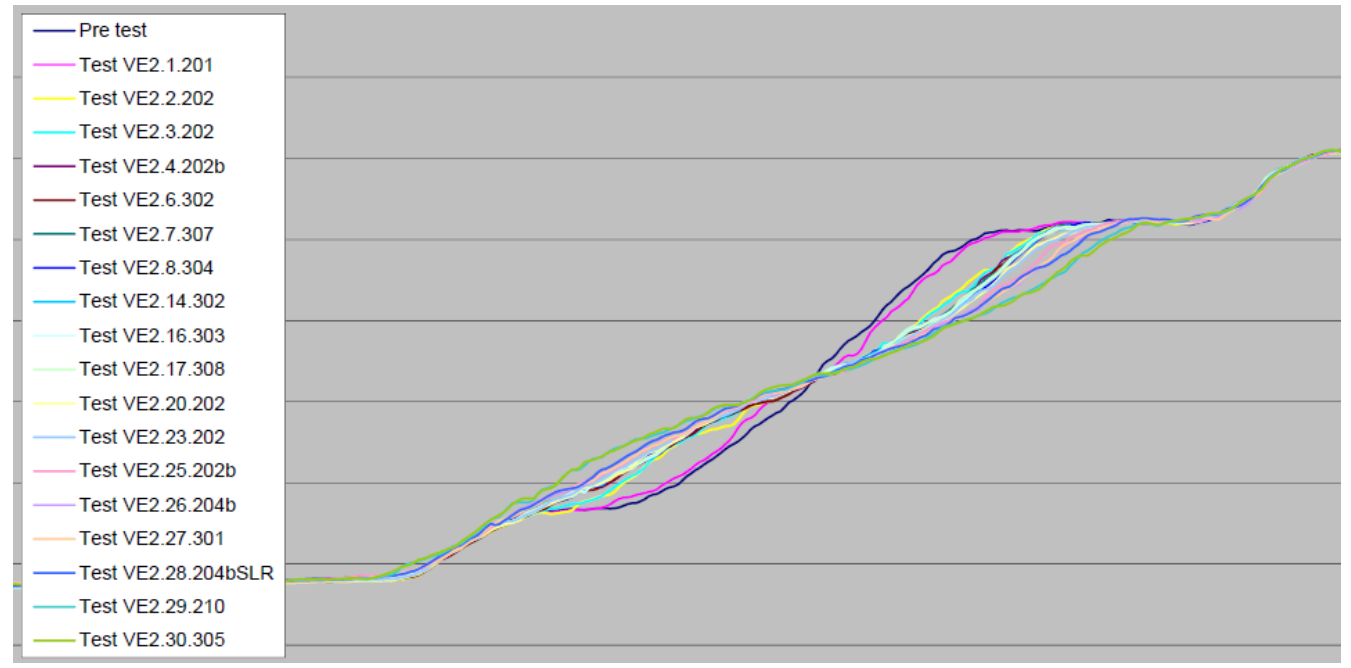

Figure 6. Test Results, Profile Development.

\section{CONCLUSION}

The following conclusions can be drawn from this work:

- The Project Delivery model, with 10 year handover and 100 year life requirements led to a need to understand the design life exposure the mass armoured berm breakwater would be subjected to.

- Statistical analysis of the design life exposure lead to the development of an extended physical modelling program to ensure that the berm breakwater design was subjected to the estimated number of storm events.

- The 3D testing program consisted of 30 separate tests, planned around the 10 year, 100 year and 1000 year overload stages of the expected breakwater life

- The oscillating test sequence that was adopted revealed the complicated nature of the mass armoured berm breakwater response.

- The results allowed quantification of the berm erosion and reshaping under design life exposure.

- We believe a best practice approach has been implemented, combined with independent peer review of the work and testing laboratory compliance reporting .

\section{ACKNOWLEDGMENTS}

We would like to thank the peer reviewers of the original project work: Mr. Steve Buchan, RPS Metocean, Perth (Design life exposure) and Dr Jentsje Van der Meer (Model testing and berm 
breakwater). Additionally we would like to thank HR Wallingford and it's staff for their perseverance in this projects extended modelling program. Finally, we thank Oakajee Port \& Rail Pty Ltd for their permission to present this work.

\section{REFERENCES}

WorleyParsons, 2011. Mass Armoured Berm Breakwater (Value Engineering) Concept Design Report, Oakajee Port \& Rail Project. 301012-01054-1130-MA-REP-0007.

HR Wallingford, 2011. 3D Physical Model Tests for Value Engineering Series VE2, Oakajee Port \& Rail Project. 301012-01054-1131-MA-REP-0034.

WorleyParsons, 2011. Mass Armoured Berm Breakwater (Value Engineering) Report of Preliminary Design, Oakajee Port \& Rail Project. 301012-01054-1130-MA-REP-0010. 